\title{
Indoor environmental conditions of athletic halls: experimental and numerical investigation
}

\author{
O. I. Stathopoulou ${ }^{1} \&$ V. D. Assimakopoulos ${ }^{2}$ \\ ${ }^{1}$ Department of Applied Physics, Faculty of Physics, \\ University of Athens, Greece \\ ${ }^{2}$ Institute for Environmental Research and Sustainable Development, \\ National Observatory of Athens, Greece
}

\begin{abstract}
Computational Fluid Dynamics (CFD) codes are widely used in environmental studies of wind flow and pollutant dispersion around buildings. In recent years they have also been applied to simulations of indoor airflows for optimal building design and ventilation. However, these applications mainly concern indoor environments such as industry working areas and offices for occupational health and safety reasons. This study investigates experimentally and numerically the environmental conditions prevailing in a large mechanically ventilated athletic hall using the commercial CFD code PHOENICS. After the model was built it was compared with experimental measurements obtained during a ten-day campaign in the hall. The collected data included airflow characteristics and pollutants concentrations at different locations of the indoor space as well as the surface temperatures of indoor materials under different ventilation conditions and occupancy of the hall. Having obtained good agreement between simulated and experimental results, the environmental conditions in the hall were investigated when half-full on an "athletic event" day and in the presence of indoor pollutants sources. Results revealed dynamic airflow, temperature and pollutant concentration patterns prevailing in the hall, significantly altering with the different scenarios applied. Airflow fields were characterized by distinct vortices originating from the ceiling air inlets of the ventilation system, while temperature and pollution stratification were observed relating to ineffective performance of the mechanical ventilation.
\end{abstract}

Keywords: athletic hall, CFD model, indoor conditions, indoor air quality, athletic event. 


\section{Introduction}

In the recent years indoor air quality has become an important issue since people nowadays spend more than $80 \%$ of their time indoors. Studies have concentrated on the measurement of pollutants concentrations in indoor environments, such as residences, offices, shopping malls and restaurants, giving a comparison of their pollution status and identifying the sources of the pollutants (Lee et al. [5], Lee et al. [6], Li et al. [7]). Studies of similar topics have examined the relation of indoor pollutants concentrations to ventilation characteristics (Guo et al. [3]). Other studies have investigated numerically the airflow prevailing in indoor environments with respect to their ventilation (Xing et al. [11]) and the dispersion of pollutants in working areas, for health and safety reasons (Cheong et al. [1], Duci et al. [2]).

However, few studies combine theoretical with experimental methods and research on large indoor public places such as stadiums and athletic halls is limited (Junker et al. [4], Stathopoulou and Assimakopoulos [10]). The matter of acceptable air quality and comfortable environmental conditions in these places where a large number of people are present during events and athletes train and contest is of major concern. Proper ventilation and supply of fresh air play a significant role in the control of indoor air quality and thermal comfort given that metabolism is intense due to the overcrowding of people. Therefore, this study investigates experimentally and numerically the environmental conditions prevailing in a large indoor basketball hall during a "big athletic" event, under mechanical ventilation conditions.

\section{Methodology}

\subsection{Experimental procedure}

A ten-day experiment took place in an indoor basketball hall built in 2000 and situated in the eastern suburbs of Thessaloniki - Greece. Parking areas and auxiliary athletic facilities surround the hall. The close vicinity includes heavytraffic roads at about $500 \mathrm{~m}$ and the sea at about $1 \mathrm{~km}$ to the southwest. The height of the indoor space is $22 \mathrm{~m}$, the arena is $1125 \mathrm{~m}^{2}$ and the capacity of the hall is 8.000. The windows are normally closed and the Heating - Ventilating - Air Conditioning (HVAC) system operates according to the needs. Measurements were taken at different locations in the hall with the HVAC system being in operation. Instrumentation included DANTEC FlowMasters giving spot mean air velocity, temperature and turbulence intensity measurements. Surface temperatures of indoor materials were measured with infrared thermometer and $\mathrm{CO}_{2}$ concentration measurements were taken using portable instrumentation.

\subsection{Theoretical model: initial and boundary conditions}

The PHOENICS CFD code (Spalding [9]) solves the time averaged conservation equations of mass, momentum, energy and chemical species in steady threedimensional flows: 


$$
\frac{\partial}{\partial t}(\rho \Phi)+\operatorname{div}\left\{\left(\rho v \Phi-\Gamma_{\Phi} \operatorname{grad}_{\Phi}\right)\right\}=S_{\Phi}
$$

where $\rho, v, \Gamma_{\Phi}$ and $S_{\Phi}$ are density, velocity vector, "effective exchange coefficient of $\Phi$ " and source rate per unit volume, respectively. The discretization of the domain is followed by the reduction of the previous equations to their finite domain form using the "hybrid formulation of the coefficients" and the solution technique employs the SIMPLEST algorithm (an improved version of the well-known SIMPLE algorithm). The standard k- $\varepsilon$ turbulence model is applied, while buoyancy effects are considered. To improve convergence, under-relaxation was used.

A three-dimensional rectangular enclosure was considered in Cartesian coordinate system (Figure 1). For symmetry reasons only one fourth of the indoor space was modelled. The dimensions of the objects are real and the geometry is as detailed as possible according to the building's plans and the mechanical ventilation system's blueprints, always taking into account computational efficiency. The domain size is $45 \mathrm{~m} \times 45 \mathrm{~m} \times 22 \mathrm{~m}$ and it includes 81 rows of spectators' seats, 23 circular air-inlet fans at the ceiling and 8 airoutlets close to floor level.

The cases studied are the following and the settings of each case are shown in Table 1. (1) Basic Case: Corresponds to a selected day from the experimental campaign. The hall is empty and the HVAC system operates without heating or cooling. (2) Event Case: The hall is assumed half-full on an "athletic event" day and ventilation conditions are same with Basic Case.

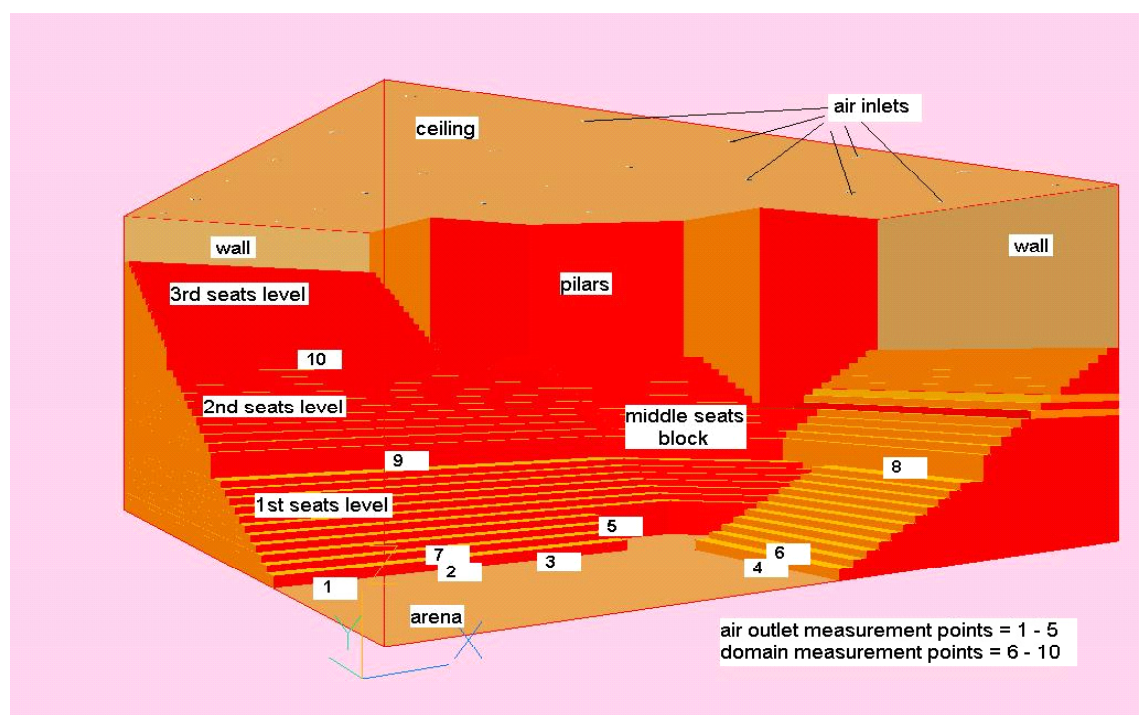

Figure 1: Geometrical domain. 
The boundary and initial conditions are: (a) Fresh air comes in the hall via the ceiling circular fans with mean (axial along $-\mathrm{z}$ ) velocities of $1.18-3.38 \mathrm{~m} / \mathrm{sec}$ and turbulence intensities of 13-31\%, according to the diameter of each fan and based on the experimental measurements. (b) The X-Z and Y-Z planes of the domain have symmetry boundary conditions (Figure 1). (c) People in the Event Case are modelled as heat and scalar sources emitting metabolic $\mathrm{CO}_{2}$, while they are distributed in the hall in proportion to the volume of the seats. Initial $\mathrm{CO}_{2}$ concentration was given according to the experimental data. This value corresponds to the concentration measured very close to the spectators while attending the event. It was selected from a series of measurements on several "event" days of the experimental period.

It should also be stated that many efforts were made to achieve the best balance among convergence, grid independency and saving of run-time due to the high complexity of the domain geometry.

Table 1: Information and input model data. The asterisk (*) corresponds to experimentally measured data.

\begin{tabular}{ccc}
\hline Data & Basic Case & Event Case \\
\hline Grid cells & $71 \times 107 \times 46$ & $91 \times 142 \times 48$ \\
Min cell size $(\mathrm{m})$ & $0.63 \times 0.42 \times 0.48$ & $0.49 \times 0.3 \times 0.46$ \\
Inlet air temp. $\left({ }^{0} \mathrm{C}\right)$ & $* 20.7-21.3$ & $* 20.7-21.3$ \\
Initial indoor air temp. $\left({ }^{0} \mathrm{C}\right)$ & $* 20.2$ & $* 20.2$ \\
Ceiling surface temp. $\left({ }^{\circ} \mathrm{C}\right)$ & $* 22$ & $* 22$ \\
Floor surface temp. $\left({ }^{0} \mathrm{C}\right)$ & $* 19$ & $* 19$ \\
East wall surface temp. $\left({ }^{\circ} \mathrm{C}\right)$ & $* 20$ & $* 20$ \\
North wall surface temp. $\left({ }^{\circ} \mathrm{C}\right)$ & $* 20$ & $* 20$ \\
Pillars temp. $\left({ }^{0} \mathrm{C}\right)$ & $* 17-20$ & $* 17-20$ \\
Temp. of $1^{\text {st }}$ seats level & $* 18$ & $* 18$ \\
Temp. of $1^{\text {st }}$ seats level & $* 18.5$ & $* 18.5$ \\
Temp. of $1^{\text {st }}$ seats level & $* 19$ & $* 19$ \\
Total heat emissions per person $(\mathrm{W})$ & - & 115 \\
People in the hall & - & $* 5400$ \\
\hline Initial CO 2 concentration $\left(\mathrm{mg} / \mathrm{m}^{3}\right)$ & - & 4000 \\
\hline
\end{tabular}

\section{Results and discussion}

(1) Basic Case: The results of this case were compared with the experimental data for validation purposes and satisfactory agreement was obtained between theoretical and experimental results (Stathopoulou and Assimakopoulos [10]). The Basic Case is used in this study as a reference-case to investigate the 
influence of the occupancy of the hall on the indoor environmental conditions. Since its results are presented in Stathopoulou and Assimakopoulos [10], where different operation patterns of mechanical ventilation were investigated, the necessary to this study results are briefly summarized in the following.

Regarding the airflow field, air jets squirt from the ceiling air inlets with max velocity $3.2 \mathrm{~m} / \mathrm{s}$ decreasing to $0.2 \mathrm{~m} / \mathrm{s}$ at $6.5 \mathrm{~m}$ above the arena (Figure 2 ). As going up the seats, jets become more intense with higher velocities reaching 0.9 $1.3 \mathrm{~m} / \mathrm{s}$ close to the spectators at the $3^{\text {rd }}$ seats level and $1.5 \mathrm{~m} / \mathrm{s}$ at the upper seats. Large vortices are formed between air jets with air velocity being less than $0.2 \mathrm{~m} / \mathrm{s}$, becoming more distinct above the seats.

Concerning temperature, smooth stratification is formed in the hall ranging at $17-21{ }^{0} \mathrm{C}$, with the higher values being observed close to the ceiling and the upper seats and the lower ones very close to the arena floor and the air outlets (not shown). It is finally interesting to note that mean air velocity and temperature at the height of $2 \mathrm{~m}$ above the arena, where the athletes train and compete are $0.07 \mathrm{~m} / \mathrm{s}$ and $20.8^{0} \mathrm{C}$, respectively.

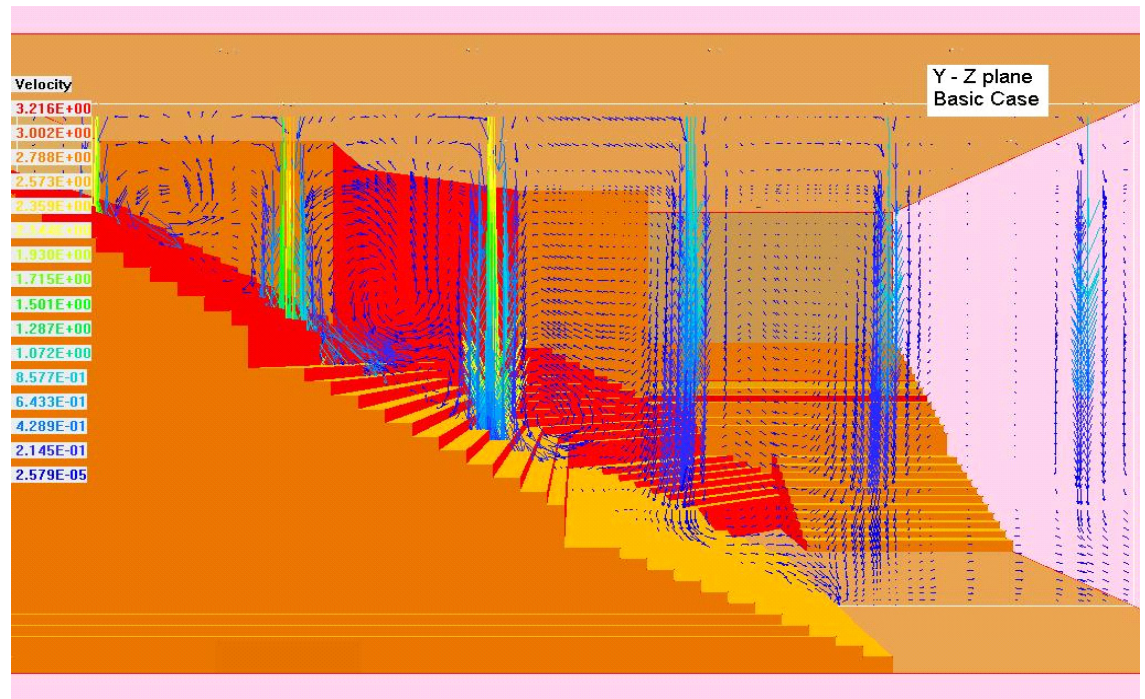

Figure 2: Vector plot of air velocity below a row of ceiling air inlets $(\mathrm{m} / \mathrm{sec})$.

(2) Event Case: The hall is $50 \%$ occupied and the air velocity field is significantly altered compared to the Basic Case (Figure 3). A single clockwise circulating vortex-like flow is formed with lower air velocities prevailing at the center area and above the arena, while higher ones near the ceiling (below the fans) and close to the spectators; especially above the middle and upper block of seats. Moving along $(+x)$ axis (see Figure 1 for $x y z$ directions) and while being below ceiling air inlet fans, the single circulating flow breaks into separate distinct vortices of relatively high velocities. Above the middle block of spectators, the complexity of the domain geometry and the location of air outlets 
favour the acceleration of the airflow with velocities reaching $0.5 \mathrm{~m} / \mathrm{sec}$. However, the mean air velocity at $2 \mathrm{~m}$ above the arena is $0.1 \mathrm{~m} / \mathrm{sec}$ and the velocity range in the domain is not considerably increased compared to the Basic Case.

Regarding temperature, a diagonal stratification is observed extending from the arena, where lower temperatures prevail, to the upper spectators, where higher values occur (Figure 4). The values along $(+x)$ axis slightly vary around $23^{\circ} \mathrm{C}$, whereas along $(+\mathrm{z})$ axis they increase from 19 to $26^{\circ} \mathrm{C}$ and along (-y) axis from 21 to $24^{0} \mathrm{C}$ (see Figure 1 for xyz directions). At the areas below the ceiling inlets, relatively colder air jets are depicted with respect to surrounding air, with penetrating depths around $5 \mathrm{~m}$ (not shown). While the mean temperature at the $2 \mathrm{~m}$-level is kept low $\left(19.7^{\circ} \mathrm{C}\right)$, the temperature range in the domain is significantly increased compared to the Basic Case $\left(17-30^{\circ} \mathrm{C}\right)$.

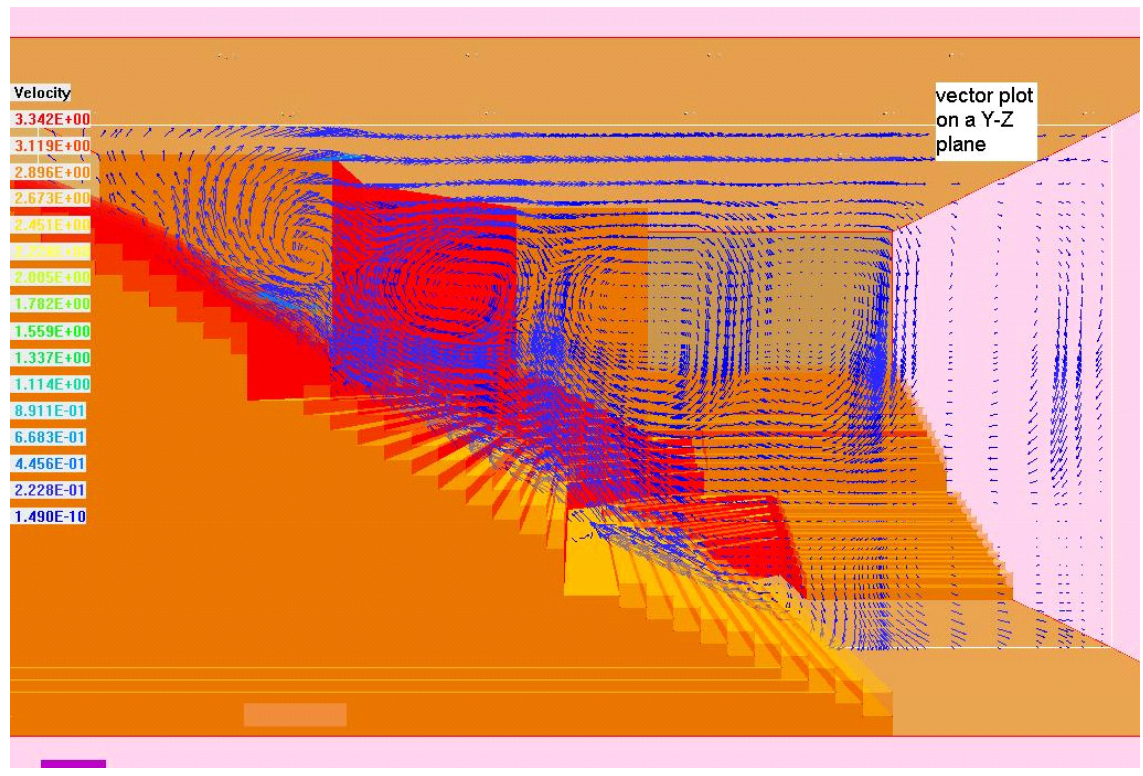

Figure 3: Air velocity field $(\mathrm{m} / \mathrm{sec})$ of Event Case.

Examining the dispersion of gaseous pollutants in the hall, the spatial distribution of $\mathrm{CO}_{2}$ concentration emitted by the people is illustrated in Figure 5. On average, the concentration of $\mathrm{CO}_{2}$ in the hall exceeds $4000 \mathrm{mg} / \mathrm{m}^{3}$. Three zones are distinguished. The first appears above the arena and the $1^{\text {st }}$ block of spectators, from about $6 \mathrm{~m}$ to $15 \mathrm{~m}$ high, with the lowest concentrations prevailing; the second occurs at about $4-19 \mathrm{~m}$ above the arena extending to the area above the $2^{\text {nd }}$ block of spectators; and the third zone includes the areas very close to the spectators and the ceiling as well as the area above the upper seats, with the highest concentrations prevailing. It seems that $\mathrm{CO}_{2}$ is forced to accumulate at the peripheral zone of the indoor space, especially at the higher 
levels among the ceiling air inlet fans. It is also important to note that pollution stratification resembles the temperature stratification observed.

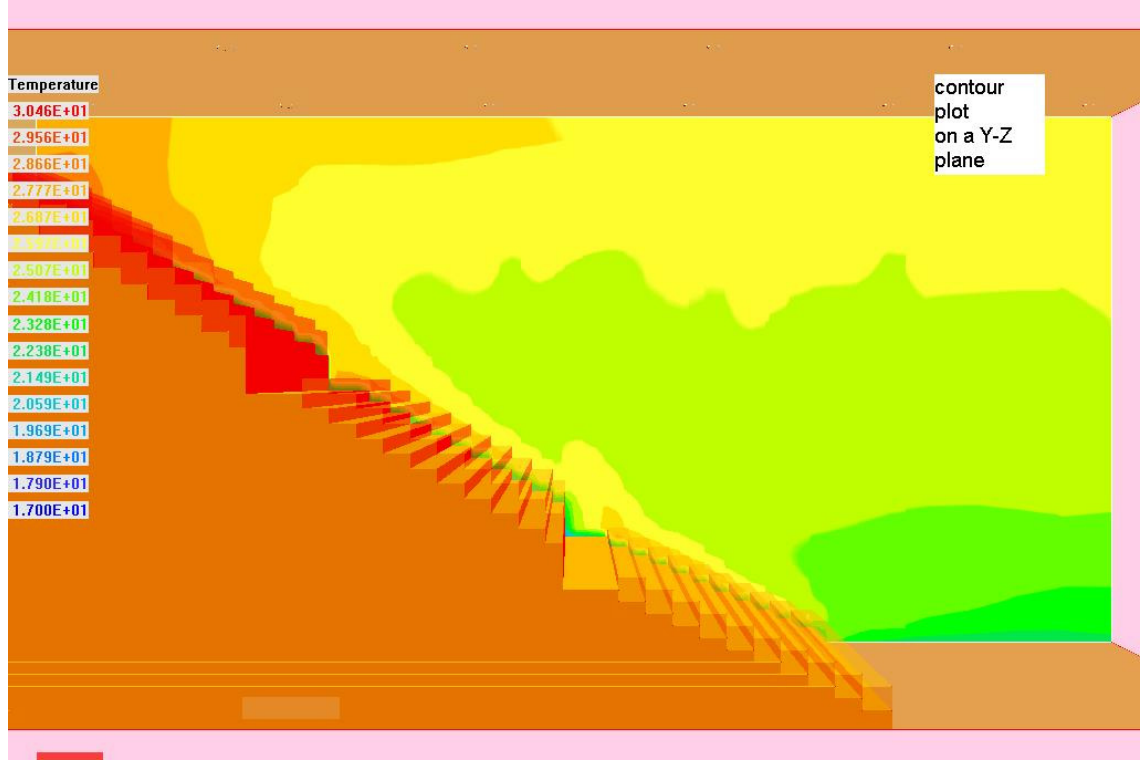

Figure 4: $\quad$ Air temperature field $\left({ }^{0} \mathrm{C}\right)$ of Event Case.

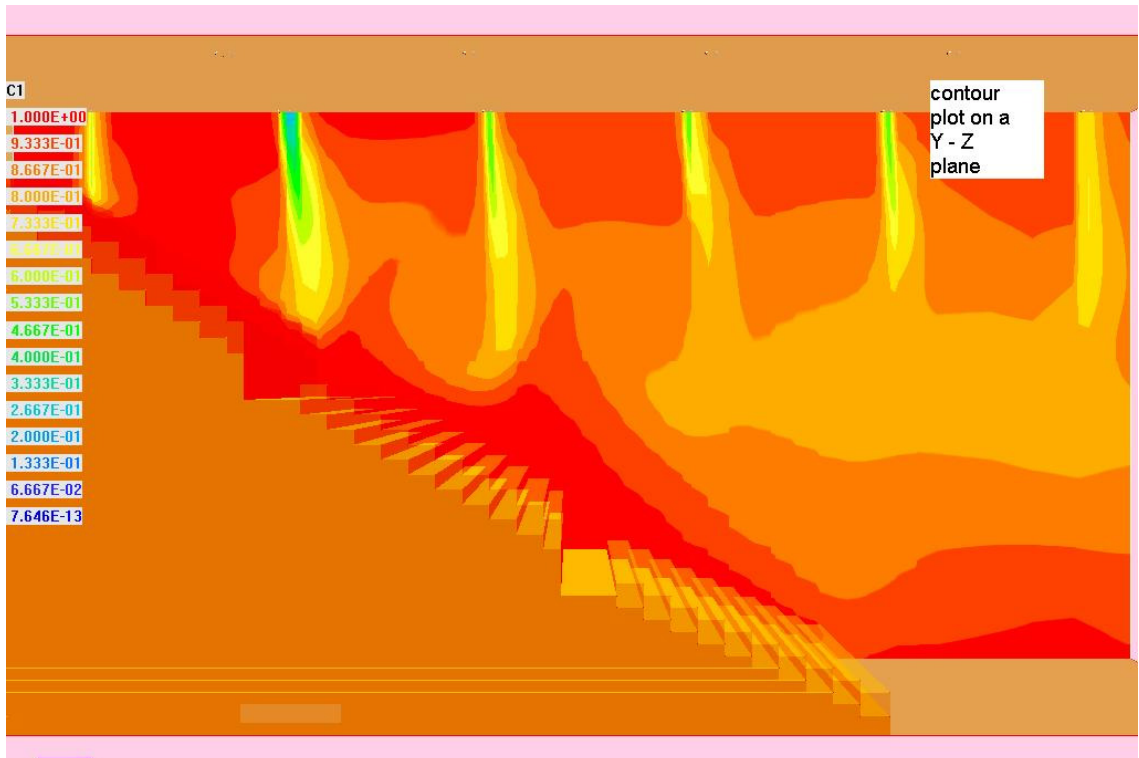

Figure 5: $\quad \mathrm{CO}_{2}$ concentration field below air inlets $\left(\mathrm{x} 5400 \mathrm{mg} / \mathrm{m}^{3}\right)$ of Event Case. 
The concentration of $\mathrm{CO}_{2}$ increases along $(+\mathrm{z})$ from 4212 to $4914 \mathrm{mg} / \mathrm{m}^{3}$, while smaller fluctuations around $4590 \mathrm{mg} / \mathrm{m}^{3}$ are observed as we move along $\mathrm{x}$ and $\mathrm{y}$ - axes. Above the arena and up to $2 \mathrm{~m}$, which is approximately the breathing height of the athletes, $\mathrm{CO}_{2}$ concentrations remain below $4212 \mathrm{mg} / \mathrm{m}^{3}$. Values lower than the previous are only observed very close to the ceiling air inlet fans, from where "clean" $\left(\mathrm{CO}_{2}\right.$ free) air is injected in the hall indicating ineffective performance of the HVAC system.

\section{Conclusion}

The airflow patterns prevailing in the investigated athletic hall with mechanical ventilation were characterised by large distinct vortices extending from top to bottom between air jets originating from the ceiling air inlet fans. Air velocities were higher at the upper spectators' seats, while temperature revealed a smooth stratification with height. When the hall was half-full (on the "event" day), a single vortex-like airflow pattern was formed breaking into smaller vortices at the areas between consecutive rows of ceiling air inlets. Air velocities in the domain did not however considerably change as opposed to the maximum temperature values which almost doubled. The temperature stratification was enhanced along the "arena - upper seats" line and related well with the pollution stratification observed in the hall. The concentration of $\mathrm{CO}_{2}$ in the indoor air was relatively high with small spatial variations, indicating ineffective performance of the ventilation system.

Further work is currently in progress including scenarios of ventilation strategies and pollutant sources as well as consideration of more physical processes. Also, a quantitative estimation is being done of the dynamic effect of different quantity of audience occupying the hall on its indoor environmental conditions.

\section{Acknowledgements}

The project is co-financed within Op. Education by the ESF (European Social Fund) and National Resources (IRAKLEITOS).

\section{References}

[1] Cheong, K.W.D., Djunaedy, E., Poh, T.K., Tham, K.W., Sekhar, S.C., Wong, N.H. \& Ullah, M.B., Measurements and Computations of Contaminants - Distribution in an Office Environment. Build. Environ. 38, pp. 135-145, 2003.

[2] Duci, A., Papakonstantinou, K., Chaloulakou, A. \& Markatos N., Numerical Approach of Carbon Monoxide Concentration Dispersion in an Enclosed Garage. Build. Environ. 39, pp. 1043-1048, 2004.

[3] Guo, H., Lee, S.C. \& Chan, L.Y., Indoor Air Quality Investigation at Airconditioned and non Air-conditioned Markets in Hong Kong. Sci. Total Environ. 323, pp. 87-98, 2004. 
[4] Junker, M., Koller, T. \& Monn, C., An Assessment of Indoor Air Contaminants in Buildings with Recreational Activity. Sci. Total Environ. 246, pp. 139-152, 2000.

[5] Lee, S.C., Li, W. \& Ao, C., Investigation of Indoor Air Quality at Residential Homes in Hong Kong. Atmos. Environ. 36, pp. 225-237, 2002.

[6] Lee, S.C., Guo, H., Li, W.M. \& Chan, L.Y., Inter-comparison of Air Pollutant Concentrations in Different Indoor Environments in Hong Kong. Atmos. Environ. 36, pp. 1929-1940, 2002.

[7] Li, W., Lee, S.C. \& Chan, L.Y., Indoor Air Quality at Nine Shopping Malls in Hong Kong. Sci. Total Environ. 273, pp. 27-40, 2001.

[8] Santamouris, M. \& Asimakopoulos, D., (eds). A Manual for Conscious Design and Operation of A/C Systems, Publication Series: Energy Conservation in Buildings, University of Athens - European Commission Directorate General XVII for Energy, Athens, May 1995.

[9] Spalding D.B., A General Purpose Computer Program for Multidimensional One- and Two-phase Flow. Mathematics and computers in simulation, 23, pp. 267-276, 1981.

[10] Stathopoulou, O.I. \& Assimakopoulos, V.D., Application of PHOENICS to Athletic Halls with HVAC Ventilation. Proc. of the $26^{\text {th }}$ Int. Conf. on Ventilation in Relation to the Energy Performance of Buildings, eds. IEA - AIVC, Belgium, 2005.

[11] Xing, H., Hatton, A. \& Awbi, H.B., A Study of the Air Quality in the Breathing Zone in a Room with Displacement Ventilation. Build. Environ. 36, pp. 809-820, 2001. 